\title{
Synthesis of Layered Organic-Inorganic Nanocomposites of Zinc and Copper by Laser Ablation in Liquid
}

\author{
V. T. Karpukhin, M. M. Malikov, T. I. Borodina, G. E. Val'yano, and O. A. Gololobova
}

Joint Institute for High Temperatures, Russian Academy of Science, 125412 Moscow, Russia

Correspondence should be addressed to M. M. Malikov, mmalikov@oivtran.ru

Received 5 March 2012; Revised 21 June 2012; Accepted 9 July 2012

Academic Editor: Jin Zhang

Copyright (๑) 2012 V. T. Karpukhin et al. This is an open access article distributed under the Creative Commons Attribution License, which permits unrestricted use, distribution, and reproduction in any medium, provided the original work is properly cited.

\begin{abstract}
The experimental data of studies of layered organic-inorganic nanocomposites $\left((\beta)-\mathrm{Zn}(\mathrm{OH})_{2}+\mathrm{DS}\right)$ and $\left(\mathrm{Cu}_{2}(\mathrm{OH})_{3}+\mathrm{DS}\right)$ which were produced in the result ablation of zinc and copper in aqueous solutions of surfactants-dodecyl sodium sulfate (SDS) and sodium bis-ethylhexyl succinate (AOT) — are presented. Dependence of the formation dynamics of these composites on an exposure time of radiation and on an aging time of colloids was studied by the absorption spectroscopy, by X-ray diffraction, by scanning electron (SEM), and atomic force microscopy (AFM). Composite $\left(\mathrm{Cu}_{2}(\mathrm{OH})_{3}+\mathrm{DS}\right)$ with bilayered structure was produced by method of laser ablation of the copper metal target in liquid for the first time.
\end{abstract}

\section{Introduction}

Layered organic-inorganic hybrid nanocomposites are of an interest according to their usage in science and technologies. They include a wide class of such chemical compounds as (1) layered double hydroxides, (2) hydroxides of double salts of metals (HDS's), and (3) some hydroxides of metals in which organic anions are intercalated between layers.

A structural variability of these compounds manifests itself in the emergence of new chemical and physical properties such as variable magnetism [1,2], efficient catalysis, adsorption, and high ion-exchange capacity [3]. Usage of such nanocomposites can give a chance to improve the mechanical and thermal stability of polymers in which composites imbedded [4] and to create new optoelectronic devices (stochastic lasers, LEDs, and sensors [5-7]). Layered materials have a potentiality to be applied in pharmacology and medicine [8].

A large number of publications was devoted to synthesis and studies of chemical properties of layered nanocomposites [3]. In the last decade a method of laser ablation of metals in liquids was used for the synthesis of metal, oxide, and hydroxide nanostructures [9]. But there are only few studies on the formation of layered organic-inorganic composites by this method.
In the present paper the authors submit the result of the study of the synthesis of some layered nanocomposites of transition metals zinc and copper. The synthesis was carried out by laser ablation of metal targets in aqueous solutions of surfactants. The synthesized materials are of the second and the third groups of composites. Their structural formulas are as follows: $(\mathrm{M})_{2}(\mathrm{OH})_{3} \mathrm{X} * \mathrm{z} * \mathrm{H}_{2} \mathrm{O}$ and $(\mathrm{M})(\mathrm{OH})_{2} \mathrm{X}$ $* \mathrm{z} * \mathrm{H}_{2} \mathrm{O}$, where $\mathrm{M}$ is divalent metals $(\mathrm{Zn}, \mathrm{Cu})$, and $\mathrm{X}$ is intercalated anion alkyl sulfate $\left(\mathrm{C}_{n} \mathrm{H}_{2 n+1} \mathrm{SO}_{4}{ }^{-}\right.$, where $\left.n=12\right)$.

In the presented study the copper vapor laser (CVL) with an output power $P_{\text {out }}-10-15 \mathrm{~W}$, pulse duration $\tau_{p}=20 \mathrm{~ns}$, and pulse repetition frequency $f_{p}=10 \mathrm{kHz}$ was used.

\section{Description of the Experiment}

A number of original papers and reviews describe a technique of the laser ablation of materials in liquids $[9,10]$. In our experiments we used CVL emission at two wavelengths: -510 and $578 \mathrm{~nm}$; the ratio of radiation power in the lines was $2: 1$, respectively. The laser beam was focused on the surface of a target by achromatic lens with a focal length $f=280 \mathrm{~mm}$, so a spot size was less than 100 microns. The target was placed in a cell with deionized water or aqueous solutions of surfactants. The volume of liquid in the 
cell was about $2 \mathrm{~cm}^{3}$. The cell was placed in the container cooled by water at $330 \mathrm{~K}$ temperature. The container was fixed upon a movable stage so that the focal spot could be shifted continually on the target surface. We used SDS $\left(\mathrm{C}_{12} \mathrm{H}_{25} \mathrm{SO}_{4} \mathrm{Na}\right)$ and AOT $\left(\mathrm{C}_{20} \mathrm{H}_{37} \mathrm{NaO}_{7} \mathrm{~S}\right)$ surfactants from the group of anionic surfactants. The surface activity of AOT surfactant is substantially higher than that of SDS according to a larger number of hydrocarbon groups. In addition to solutions of SDS and AOT in water $0.15 \mathrm{M}$ solution of AOT in nonan $\left(\mathrm{C}_{9} \mathrm{H}_{20}\right.$ is an organic compound from alkanes class) was used. It was diluted by the deionized water up to the water/AOT molar ratios $-W=5,60,700$. Formation of reverse micelles is a peculiarity of these solutions. Volume of water pool of the reverse micelles depends on $W$. Quantity and size of nanoparticles are limited by the value of $W$.

Optical parameters of the obtained colloidal solutions with nanostructures of $\mathrm{Zn}, \mathrm{ZnO}$, zinc hydrates, and other compounds were analyzed by the method of optical absorption at the spectral range from 200 to $700 \mathrm{~nm}$ by SF-46 spectrophotometer with automatic data processing system. The structure and composition of the colloidal solution's solid phase prepared by centrifugation at $4000 \mathrm{rpm}$ and dried at $320-330 \mathrm{~K}$ temperature were studied by DRON2 X-ray diffractometer $\left(K_{\alpha}\right.$ line of copper). The shape and size of nanostructures were studied with an atomic force microscope (AFM) Solver P47-PRO (in semicontact topography mode) and scanning electron microscopy (SEM) Hitachi S405A, $15 \mathrm{kV}$. Samples for AFM analysis were prepared by single or multiple smears of wet precipitate on a glass slide. Precipitates were obtained by centrifugation and by following drying at 312-323 K temperature under atmospheric conditions. A number of layers of precipitate on the glass slide were chosen empirically to achieve a sufficient sharpness of the X-ray diffraction patterns and AFM images.

\section{The Experimental Results and Discussion}

3.1. The Analysis of Zinc Ablation Products. Figures 1-3 show the absorption spectra of $A(\lambda)$ (in abs. units.) of colloidal solutions obtained at different types of surfactants and their concentrations in the initial solutions, for the exposure time $\tau_{e}$ and the colloid aging time $\tau_{\mathrm{ag}}$ at the room temperature. Curves 1-4 (Figure 1) show the absorption spectra of colloids which are products of ablation of zinc in the deionized water. In all cases the average radiation power on the target was 12$14 \mathrm{~W}$.

The analysis of the spectra shows that the increase of surfactant concentration in the solution above the critical value strongly changes the optical properties of the colloids. The critical concentration is defined by the beginning of micelles formation in the colloid (for SDS $-0.008 \mathrm{M}$, and for $\mathrm{AOT}<0.01 \mathrm{M})$. In the most cases the absorption in freshly prepared colloid ( $\tau_{\mathrm{ag}}<30 \mathrm{~min}$ ) increases from a half to two times in the ultraviolet range $(\lambda<350 \mathrm{~nm})$ and in two or more times in the visible range $(\lambda>400 \mathrm{~nm}$ ) (see Figures 1,2 , and 3$)$. The maximum absorption $(A>0.9)$ was achieved in the ultraviolet range of the spectra in a solution of $0.15 \mathrm{M} \mathrm{AOT}+$ nonan $+\mathrm{H}_{2} \mathrm{O}$. A similar result was obtained

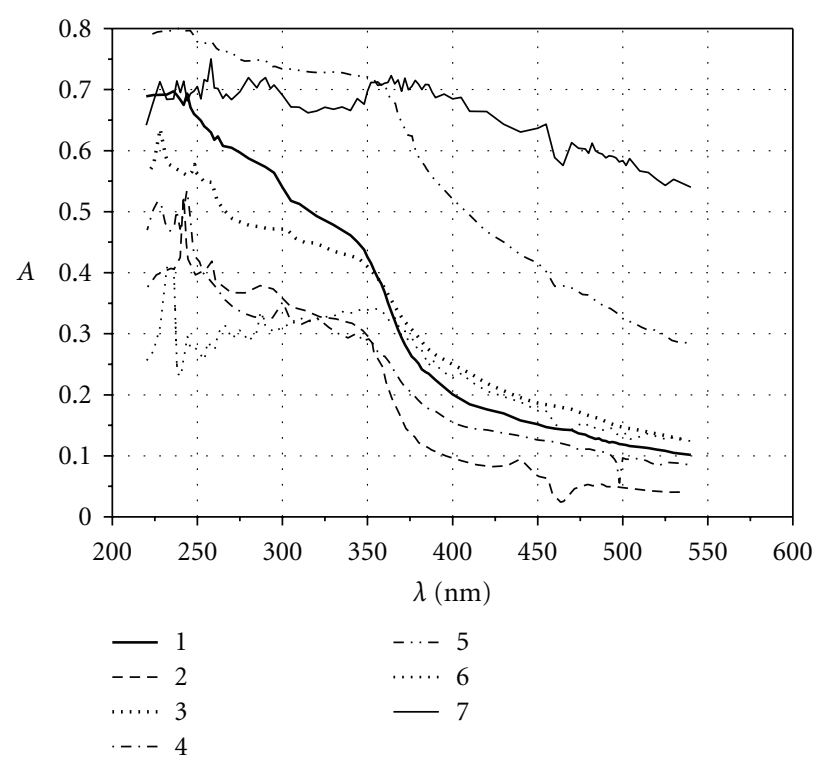

FIgURE 1: The absorption spectra $A(\lambda): 1-4: \mathrm{Zn}+\mathrm{H}_{2} \mathrm{O} ; 1: \tau_{\text {ag }}=$ $5 \mathrm{~min}, \tau_{e}=35 \mathrm{~min} ; 2: \tau_{\mathrm{ag}}=3.5 \mathrm{~h}, \tau_{e}=35 \mathrm{~min} ; 3: \tau_{\mathrm{ag}}=15 \mathrm{~min}, \tau_{e}=$ $3 \mathrm{~h} 10 \mathrm{~min} ; 4: \tau_{\mathrm{ag}}=1 \mathrm{~h} 40 \mathrm{~min}, \tau_{e}=3 \mathrm{~h} 10 \mathrm{~min} ; 5-7: \mathrm{Zn}+0.001 \mathrm{SDS}$; 5: $\tau_{\mathrm{ag}}=7 \mathrm{~min}, \tau_{e}=30 \mathrm{~min} ; 6: \tau_{\mathrm{ag}}=3.5 \mathrm{~h}, \tau_{e}=30 \mathrm{~min} ; 7: \tau_{\mathrm{ag}}=30 \mathrm{~min}$, $\tau_{e}=3 \mathrm{~h}$.

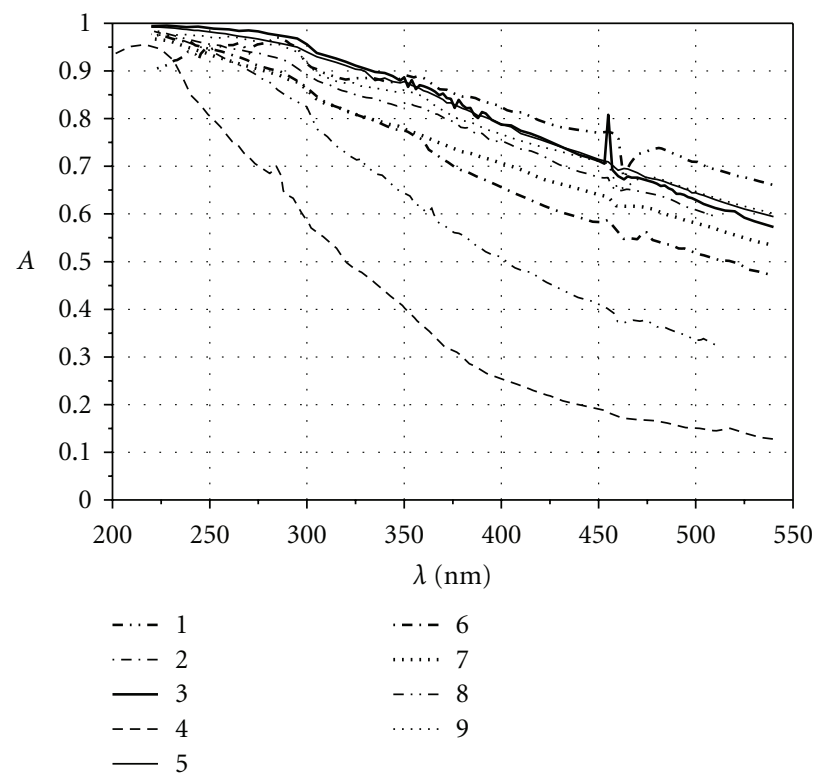

FIGURE 2: The absorption spectra $A(\lambda): 1-4 \mathrm{Zn}+0.01 \mathrm{M}$ SDS; 1: $\tau_{\mathrm{ag}}=10 \mathrm{~min}, \tau_{e}=30 \mathrm{~min} ; 2: \tau_{\mathrm{ag}}=22 \mathrm{~h}, \tau_{e}=30 \mathrm{~min} ; 3: \tau_{\mathrm{ag}}=10 \mathrm{~min}$, $\tau_{e}=2 \mathrm{~h} ; 4: \tau_{\mathrm{ag}}=19 \mathrm{~h}, \tau_{e}=3 \mathrm{~h} 16 \mathrm{~min} ; 5-9: \mathrm{Zn}+0.05 \mathrm{M} \mathrm{SDS} ; 5: \tau_{\mathrm{ag}}=$ $7 \mathrm{~min}, \tau_{e}=30 \mathrm{~min} ; 6: \tau_{\mathrm{ag}}=4.5 \mathrm{~h}, \tau_{e}=30 \mathrm{~min} ; 7: \tau_{\mathrm{ag}}=24 \mathrm{~h}, \tau_{e}=$ $30 \mathrm{~min} ; 8: \tau_{\mathrm{ag}}=20 \mathrm{~min}, \tau_{e}=2 \mathrm{~h} ; 9: \tau_{\mathrm{ag}}=19 \mathrm{~h}, \tau_{e}=2 \mathrm{~h}$.

by increasing the exposure time, that is, by increasing the number of nanoparticles of zinc oxide, zinc, and other zinc compounds in the colloid. Many-hour exposure after the irradiation of colloids as a rule noticeably reduces the absorption level especially in the long-wave spectra part. 


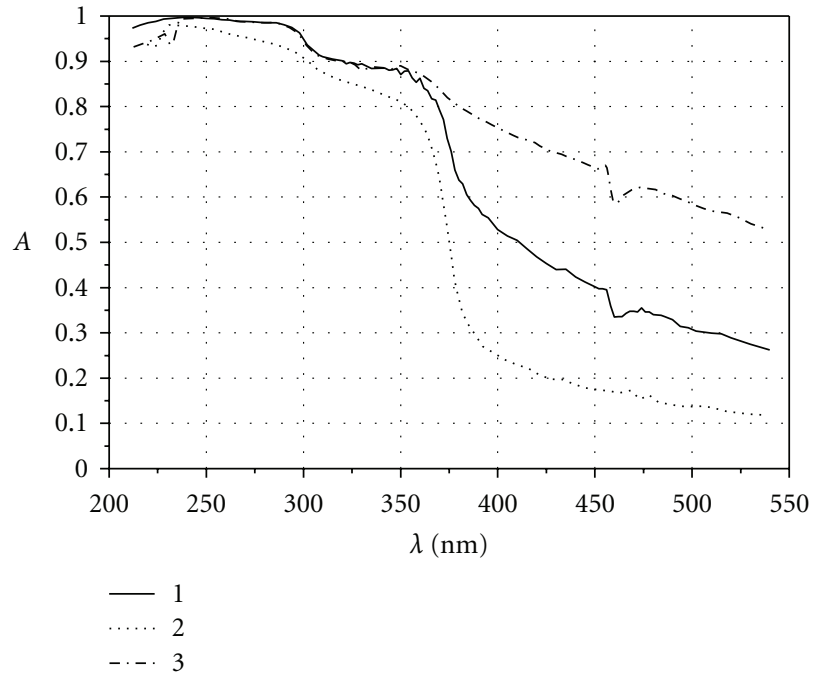

(a)

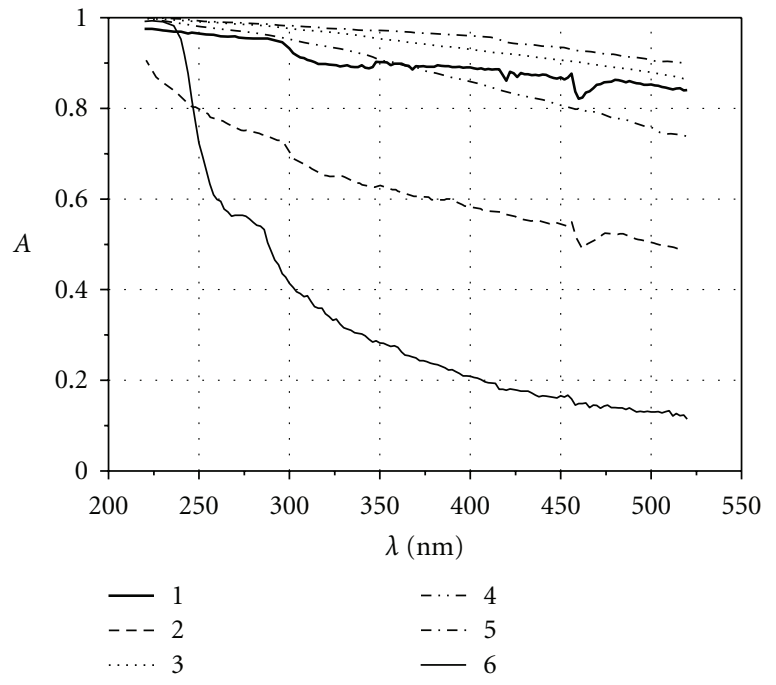

(b)

Figure 3: The absorption spectra $A(\lambda):(\mathrm{a}) 1: \mathrm{Zn}+0.05 \mathrm{M} \mathrm{AOT} ; \tau_{\mathrm{ag}}=5 \mathrm{~min}, \tau_{e}=3 \mathrm{~h} ; 2: \mathrm{Zn}+0.01 \mathrm{M} \mathrm{AOT} ; \tau_{\mathrm{ag}}=22 \mathrm{~h}, \tau_{e}=3 \mathrm{~h} ; 3: \mathrm{Zn}+0.037 \mathrm{M}$ AOT; $\tau_{\mathrm{ag}}=5 \mathrm{~min}, \tau_{e}=3 \mathrm{~h}$; (b) $\mathrm{Zn}+0.01 \mathrm{M} \mathrm{AOT:} 1: W=700 ; \tau_{\mathrm{ag}}=30 \mathrm{~min}, \tau_{e}=1 \mathrm{~h} ; 2: W=700 ; \tau_{\mathrm{ag}}=20 \mathrm{~h}, \tau_{e}=1 \mathrm{~h} ; 3: W=60 ; \tau_{\mathrm{ag}}=10 \mathrm{~min}$; $\tau_{e}=3 \mathrm{~h} ; 4: W=60 ; \tau_{\mathrm{ag}}=4 \mathrm{~h}, \tau_{e}=3 \mathrm{~h} ; 5: W=5 ; \tau_{\mathrm{ag}}=20 \mathrm{~min}, \tau_{e}=3 \mathrm{~h} ; 6: W=5 ; \tau_{\mathrm{ag}}=20 \mathrm{~h} ; \tau_{e}=3 \mathrm{~h}$.

The peaks of plasmon resonances of zinc nanoparticles $(\lambda \approx 232,242 \mathrm{~nm})$ on the curves (Figure 1) in the case of the zinc ablation in the deionized water and for the SDS concentration in the initial solution equal to $0.001 \mathrm{M}$ (substantially less than the critical concentration for the micelle formation $-0.008 \mathrm{M}$ ) almost disappear at a molarity of solutions of SDS in the water more than $0.01 \mathrm{M}$ (Figure 2). They also were not visible in the absorption spectra of the colloids when AOT $(0.01 \mathrm{M}$ and $0.037 \mathrm{M})$ and AOT + nonan $+\mathrm{H}_{2} \mathrm{O}$ were used (Figure 3 ).

The well-known band of the exciton absorption $\mathrm{ZnO}$ ( $E_{g} \approx 3.37 \mathrm{eV}$ at room temperature) was clearly determined only in cases of zinc ablation in the water, in the SDS solution with the concentration of $0.001 \mathrm{M}$ (at the time of exposure $\tau_{e}=30 \mathrm{~min}$ ) and in the $0.01 \mathrm{M}$ solution of AOT. The beginning of this band was at about $380 \mathrm{~nm}$ wavelengths. As it follows from these data, the size of the nanoparticles of the zinc oxide is mainly more than $10-15 \mathrm{~nm}$. In the spectra of other colloids this band was not observed. In addition there are the individual peaks and the specific rises at the 280-300 nm wavelengths of absorption curves of colloids obtained in the deionized water with SDS and AOT. They indicate the presence of zinc oxide particles size of $1.5-5 \mathrm{~nm}$ $[11,12]$.

The peculiarity of the absorption spectra of the almost all studied colloids is an appearance of a rather narrow $(\Delta \lambda \approx$ $20 \mathrm{~nm}$ ) range of sharp decrease of the absorption at the 450 $480 \mathrm{~nm}$ wavelengths (the peak of transparency). The peak amplitude increases as for the increase of the irradiation time and also for the increase of SDS and AOT concentrations. It should be noted that the peak amplitude notably decreases with the increase of aging time. And the peak disappears completely after centrifugation of the colloid (curve 4 in Figure 2 and curve 2 in Figure 3). These mean that the peak appearance is associated with the origin of a rather largescale particle systems in solutions which are derived from them by sedimentation or centrifugation.

A number of previous studies confirmed the nature of changes in the optical spectra of zinc oxide nanostructures synthesized by a method of laser ablation in liquids [13-15] and chemical methods [16]. In different experiments were determined changes of the absorption level in the UV and visible regions of the absorption spectra $[17,18]$, the shape and amplitude of the plasmon resonances peaks [19], and the shift of the exciton absorption band of $\mathrm{ZnO}[20,21]$. The presence of narrow peaks of transparency was reported in [22].

Interpretation of the absorption spectra of colloids is a complex task. Really the solid phase of colloid is composed of the products of chemical interaction of the zinc with the water and surfactant. They are nanoparticles of zinc, oxides and hydrates of zinc, organic-inorganic composites obtained in the processes of ablation, and the subsequent aging of the colloid. All components of the solid phase can change their size and structure in the time as a result of the processes of growth, aggregation, and coagulation. So the common shape of the optical spectra is a superposition of spectra of the plasmon resonances of different nanoparticles, the peaks and exciton absorption bands of the zinc oxide whose width depends on the particles size, and the absorption bands of other components of the colloid. As authors believe the nature of the spectra obtained in presented experiments can be explained qualitatively using physics of fractals. In particular it concerns the optical properties of the colloidal systems and composite nanostructures which are typical examples of fractal systems [23]. The theory of optical properties of fractal aggregates (FA) differs from the wellknown Mie theory for the metal nanoparticles because it 


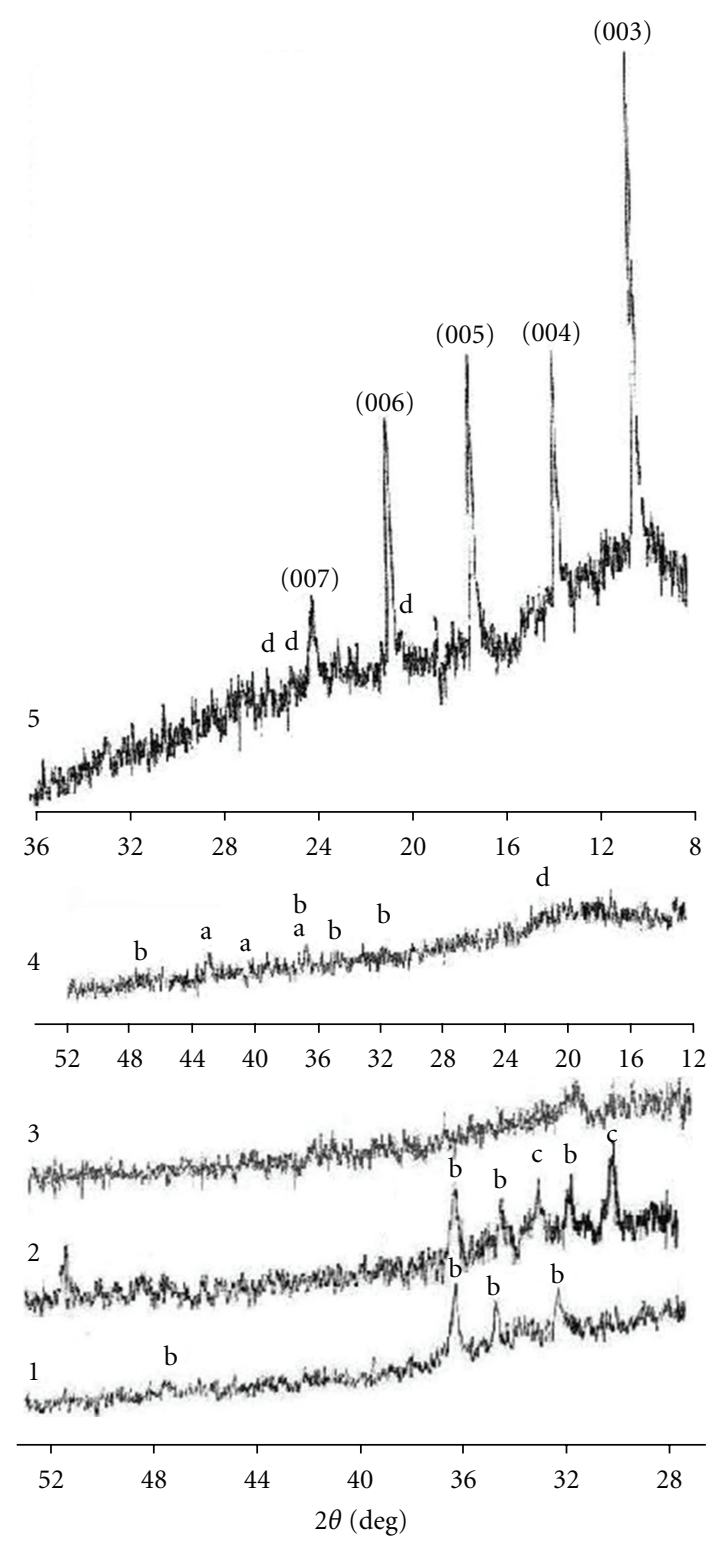

Figure 4: X-ray diffraction patterns of precipitates extracted from the colloidal solution. $1: \mathrm{Zn}+\mathrm{H}_{2} \mathrm{O} ; 2: \mathrm{Zn}+0.001 \mathrm{M}$ SDS; $3: \mathrm{Zn}+$ 0.05 M SDS; 4: Zn + 0.037 M AOT; 5: Zn + 0.01 M SDS; a: Zn, b: $\mathrm{ZnO}$, c: hydrozincite, d: $\mathrm{Zn}(\mathrm{OH})_{2}$.

takes into account an electrodynamics interaction of the adjacent particles in the fractal aggregate. Conclusions of this theory were confirmed experimentally. In accordance to this theory there are a broadening and frequency shift of plasmon resonances of fractals to the low-frequency range of spectra that is, extension of the long-wavelength part of the spectra in comparison with spectra of the system of individual noninteracting particles. The frequency shift is $\Delta \omega \sim \omega_{p}$ and it means that a mutual electrodynamics influence of adjacent particles is so high that a shift of their resonance frequency is comparable to the resonant frequency itself. The extension of the long-wavelength range of spectra increases with the increase of the fractals size. The theory of optical

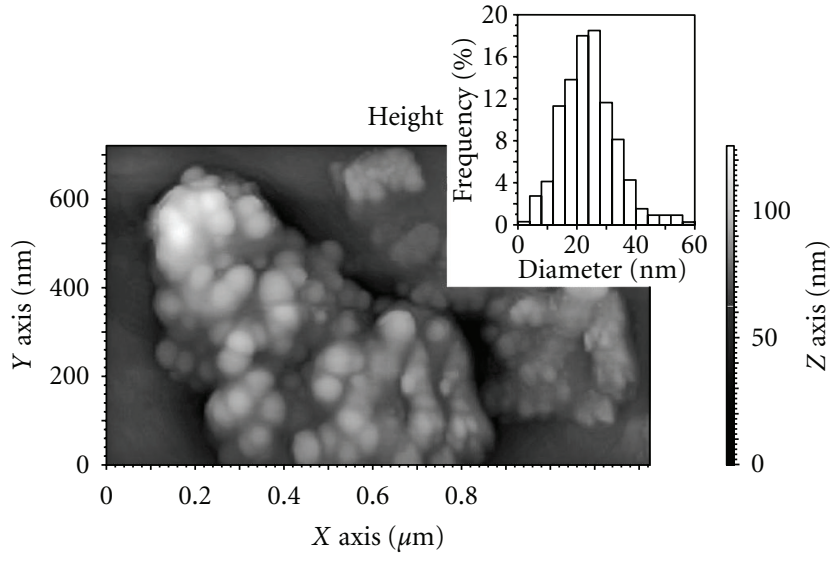

FIGURE 5: AFM image of the structure of surfaces of the preparation obtained by the laser ablation of the zinc target in the $0.001 \mathrm{M}$ SDS solution, the sample of flattened polyhedral particles with rounded edges on large plate aggregates, and the histogram of the distribution of particles.

properties of fractals in particular illustrated by the example of silver colloid particles shows the possibility of appearance of additional peaks and "dips" in the long-wavelength range of FA spectra associated with changes of the particle size distribution including the presence of surfactants in the colloid. There is also a photodynamic effect on the colloid particles with resonance frequencies close to the frequency of the incident radiation [24]. This effect leads to a rather narrow dips- "burn-through"-in the absorption spectra of the colloid.

In our experiments indicated features of the spectra-the rise of the absorption level especially in the long wavelength part of spectra, the origin of a broad peak in the $470-500 \mathrm{~nm}$ wavelength range, the presence of peaks of "transparency," and their disappearance during the sedimentation of large complexes or centrifugation-could be connected with conclusions of the theory of fractals. So the analysis of optical spectra shows the formation of fractal aggregates of different composition and shape in colloids.

This conclusion is confirmed by X-ray spectra and AFM images of the solid phase of colloids. Figure 4 presents five diffraction patterns which show variations of the Xray spectra of the precipitate in accordance to the type and concentration of surfactant in the initial solution. The diffraction pattern 1 shows a spectrum of the precipitate obtained after the zinc irradiation in the deionized water at $\tau_{e}=3.5 \mathrm{~h}$ and $\tau_{\mathrm{ag}}=40 \mathrm{~h}$. The spectra contain distinct peaks which belong to the crystalline zinc oxide. This phase has a hexagonal crystal structure with cell parameters $a=0.3294 \pm$ $0.0001 \mathrm{~nm}, c=0.5214 \pm 0.0001 \mathrm{~nm}$. The sizes of coherent scattering regions which describes the size of nanoparticles are $L_{a}=41 \mathrm{~nm}$ along the crystallographic $a$ axis and $L_{c}=$ $84 \mathrm{~nm}$ along the crystallographic $c$ axis. In this spectra peaks of the zinc are not visible. Two crystal phases are visible in spectra 2 which were obtained at $0.001 \mathrm{M}$ SDS addition to the initial solution. One of them is for $\mathrm{ZnO}$ with a hexagoal crystal structure and lattice parameters $a=0.3252 \pm 0.0001$; 


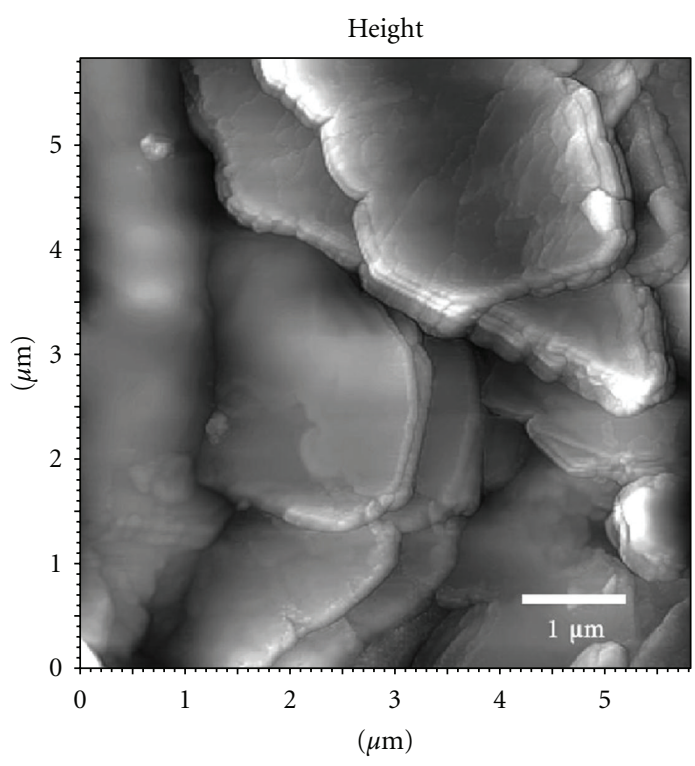

(a)

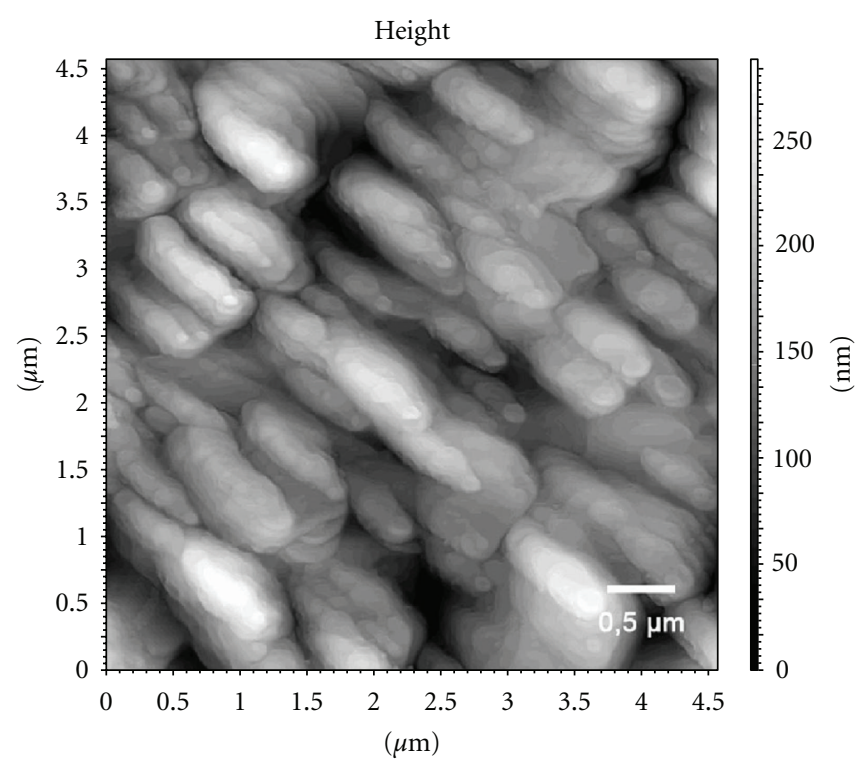

(b)

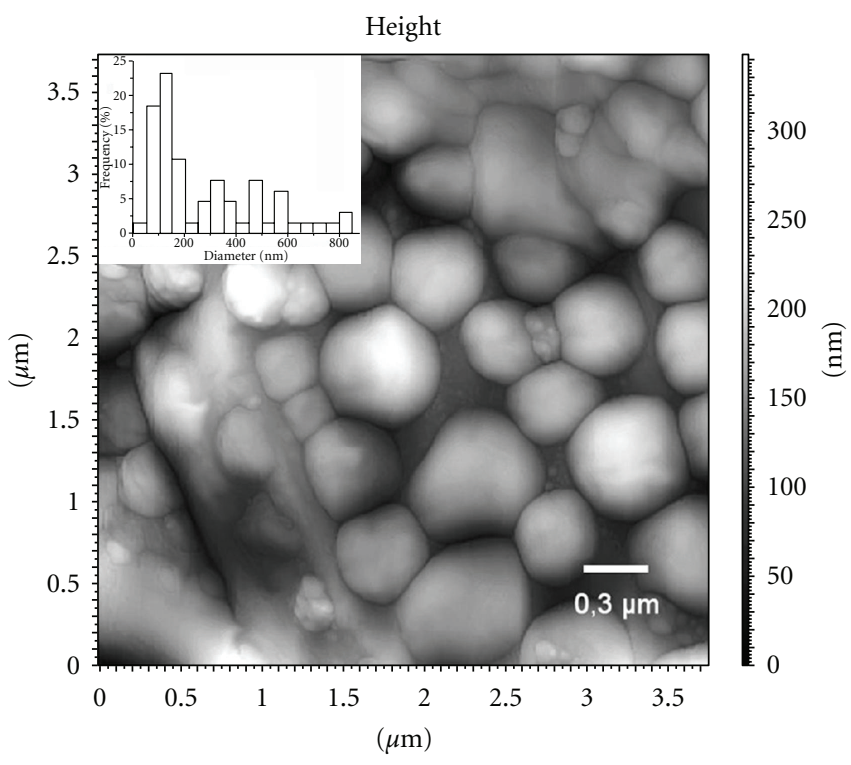

(c)

FIGURE 6: AFM image of the structure of surfaces of the preparation obtained by the laser ablation of a zinc target in the $0.01 \mathrm{M}$ solution of SDS. (a) Colony of plate particles, (b) 3D-reconstruction of the region, and (c) the sample of flattened polyhedral particles with rounded edges on the large plate aggregates, the histogram of the distribution of particles sizes.

$a=0.5199 \pm 0.0001$. The crystallites size is $40 \mathrm{~nm}$ both along the crystallographic $a$ and $c$ axes. This value is less than the same one in experiments with the deionized water. The second crystalline phase is represented in the spectra by a set of diffraction lines which coincide to the greatest degree with spectral lines of hydrozincite $\mathrm{Zn}_{5}(\mathrm{OH})_{6}\left(\mathrm{CO}_{3}\right)_{2}$. The average crystalline size of this phase is $40 \mathrm{~nm}$. Amount of hydrozincite in the precipitate is rather greater than the amount of $\mathrm{ZnO}$. Such fact was not registered in experiments with the Nd:YAG lasers known to authors.

The increase of SDS concentration $(M>0.01)$ leads to the formation of a new phase which is a layered organicinorganic composite $\mathrm{ZnDS}-\left[(\beta)-\mathrm{Zn}(\mathrm{OH})_{2}+\mathrm{DS}\right]$ formed from $(\beta)-\mathrm{Zn}(\mathrm{OH})_{2}$ and SDS (diffraction pattern 5). The average basal spacing for this phase is $d=2.7063 \mathrm{~nm}$. For the first time the similar material was registered in [25]. In accordance to [26] the SDS monohydrate serves as a template for formation of two-layer structure in which the chains of dodecyl sulfate anions are arranged perpendicularly to the $\mathrm{Zn}(\mathrm{OH})_{2}$ sheets. The spectrum 3 obtained for the solution with SDS concentration $0.05 \mathrm{M}$ shows substantial presence of the amorphous phase. The crystalline part includes a layered $\left[(\beta)-\mathrm{Zn}(\mathrm{OH})_{2}+\mathrm{DS}\right]$ and $\mathrm{Zn}(\mathrm{OH})_{2}$. The amounts of both phases are less than amount of $\mathrm{ZnO}$. An amorphous phase is also the basis of the colloidal precipitate formed in the experiment with the solution containing $0.037 \mathrm{M}$ AOT. 


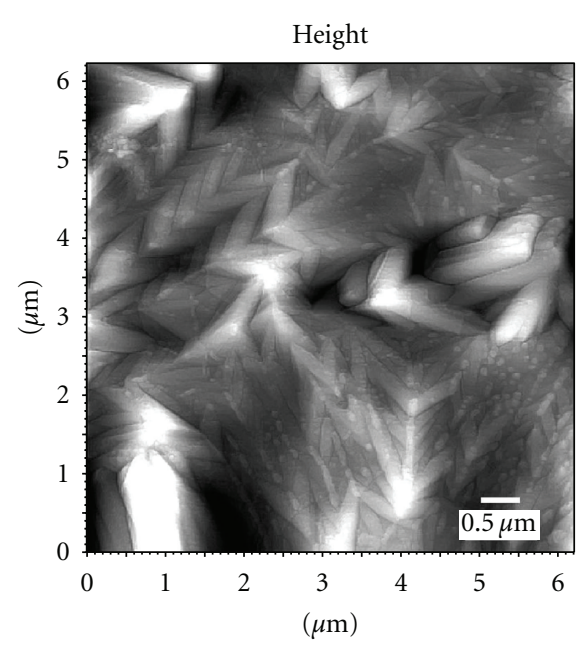

FIGURE 7: AFM image of the structure of surfaces of the preparation obtained by the laser ablation of a zinc target in the $0.037 \mathrm{M}$ solution of AOT_-pyramidal topography formed by cuneiform tablets.

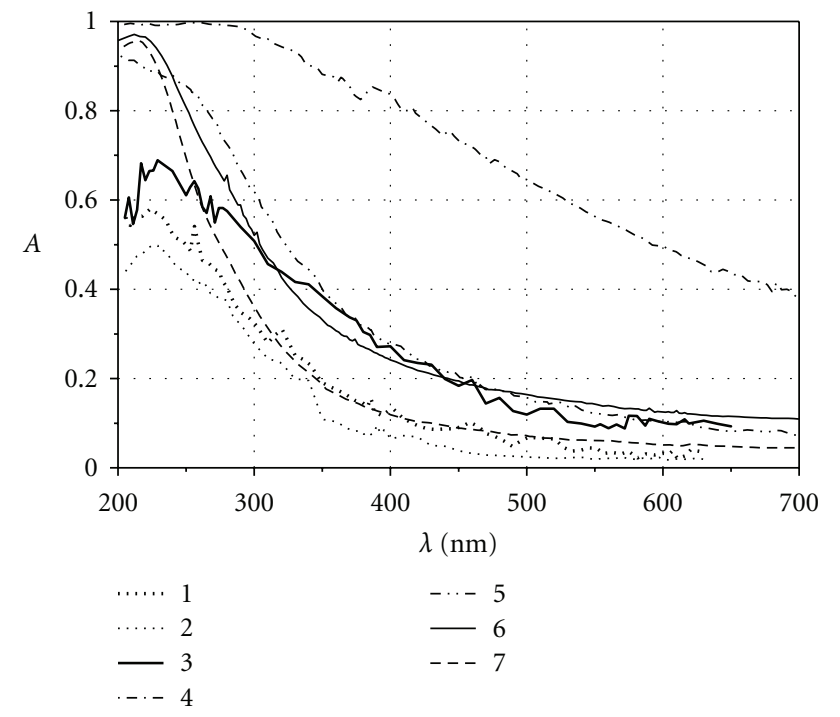

Figure 8: The absorption spectra $A(\lambda): 1-3: \mathrm{Cu}+\mathrm{H}_{2} \mathrm{O} ; 1: \tau_{\text {ag }}=$ $2 \mathrm{~min}, \tau_{e}=40 \mathrm{~min} ; 2: \tau_{\mathrm{ag}}=3 \mathrm{~h}, \tau_{e}=40 \mathrm{~min} ; 3: \tau_{\mathrm{ag}}=1.3 \mathrm{~h}, \tau_{e}=3 \mathrm{~h}$; 4-5: $\mathrm{Cu}+0.01 \mathrm{SDS} ; 4: \tau_{\mathrm{ag}}=10 \mathrm{~min}, \tau_{e}=3 \mathrm{~h} ; 5: \tau_{\mathrm{ag}}=64 \mathrm{~h}, \tau_{e}=3 \mathrm{~h}$; 6-7: $\mathrm{Cu}+0.1 \mathrm{SDS} ; 6: \tau_{\mathrm{ag}}=10 \mathrm{~min}, \tau_{e}=3 \mathrm{~h} ; 7: \tau_{\mathrm{ag}}=19 \mathrm{~h}, \tau_{e}=3 \mathrm{~h}$.

Besides the precipitate contains crystalline $\mathrm{ZnO}(85 \mathrm{~nm}), \mathrm{Zn}$ $(42 \mathrm{~nm})$, and amorphous $\mathrm{Zn}(\mathrm{OH})_{2}(\sim 1.5 \mathrm{~nm})$.

Obtained results of the X-ray diffraction as well as the data of other experiments $[25,26]$ show the following dynamics of the synthesis of nanostructures based on zinc in dependence on the concentration of anionic surfactants SDS and AOT. Only $\mathrm{Zn}$ and $\mathrm{ZnO}$ are formed by the ablation in the deionized water. Hydrozincite is obtained at concentrations lower than the critical one (0.001 M SDS) and at the high power irradiation by the CVL. A layered organicinorganic composite is formed when the SDS concentration increases to $0.01 \mathrm{M}$ in the experiments with CVL and for the long exposure $\left(\tau_{e} \sim 1 \mathrm{~h}\right)$ at low-power radiation of the

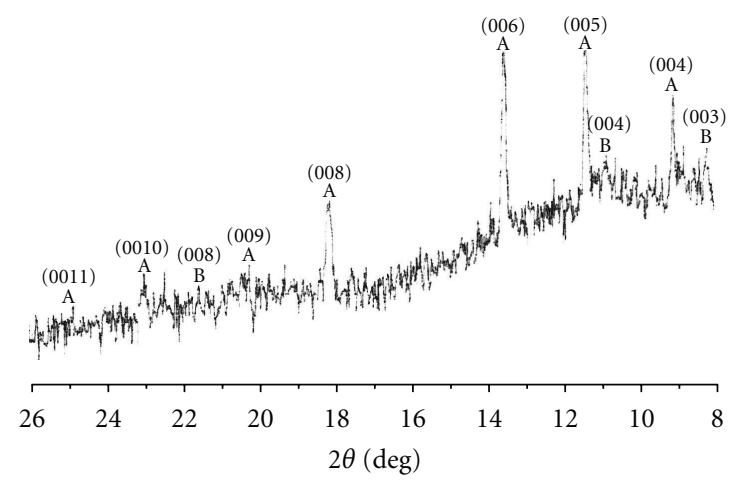

FIGURE 9: X-ray patterns of precipitates extracted from the colloidal solution $\mathrm{Cu}+0.01 \mathrm{M}$ SDS. Phases: A: he basal spacing $d=$ $3.887 \mathrm{~nm}, \mathrm{~B}: d=3.27 \mathrm{~nm}$.

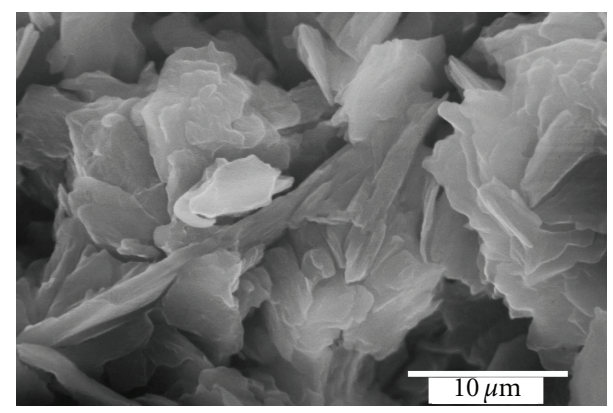

FIGURE 10: SEM image of layered structures of the preparation obtained by the laser ablation of copper target in the $0.01 \mathrm{M}$ solution of SDS.

Nd:YAG laser [25]. A further increase of the SDS and AOT concentrations results in the formation substantially of the very fine ablation products of zinc. This fact shows that surfactants are able to limit the growth of nanoparticles. At the same time an increase of the surfactant concentration in the solution promotes the growth and agglomeration of micelles into fractal structures.

Figures 5-7 present AFM images of colloid precipitates obtained, respectively, in the processing of solutions with $0.001 \mathrm{M}, 0.01 \mathrm{M}$ SDS, and $0.037 \mathrm{M}$ AOT and the histogram of the particles size distribution. The analysis of these images confirms conclusions of analysis of colloid's optical spectra and of the X-ray spectra of the solid phase. Really AFM images (Figure 5) show the formation of round shape particles with of $20-50 \mathrm{~nm}$ or less size as well as large complexes with indefinite form and with $100-400 \mathrm{~nm}$ size. Colonies (layers) of densely laid on each other plates with the cross-section size about some microns can be seen in Figures 6(a) and 6(b). It can be observed the origin of groups of oblate polyhedral particles on these plates (Figure 6(c)). Linear dimensions of these structures are mainly in 200-1000 $\mathrm{nm}$ range, and their thicknesses in the transverse direction are 4-6 times less. Similar pictures are obtained on samples with AOT (Figure 7). In this case layered structures with pyramidal shape prevail. This shape was formed by relatively large (up to $1-3 \mu \mathrm{m}$ in cross-section) tablets with 


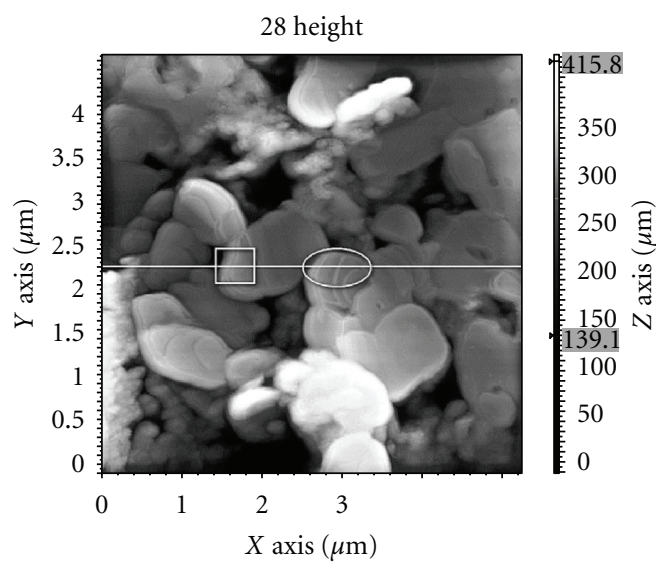

(a)

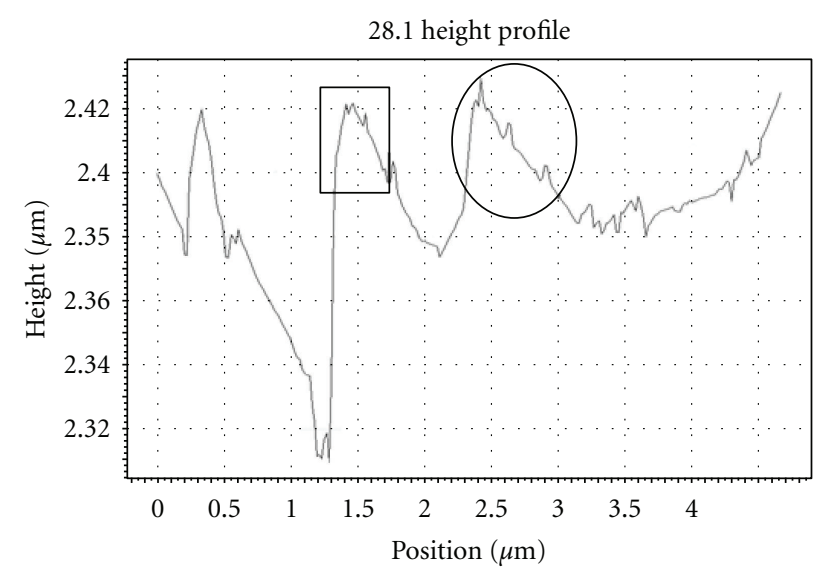

(b)

FIGURE 11: AFM image of part of the preparation obtained by the laser ablation of copper target in the $0.01 \mathrm{M}$ solution of SDS. (a) The image of structure and (b) the trace of cantilever AFM (the profile of "sandwich" edges).

conical form. Particles with $\sim 2-150 \mathrm{~nm}$ size can be seen on plates.

Thus the study of images shows that phases based on $\mathrm{Zn}$ are located inside or under phases based on SDS and AOT or form complexes with them. Let us note that such picture of the solid phase was observed in samples with the solutions aging time $\tau_{\mathrm{ag}}$ up to 40 hours. Further increase $\tau_{\mathrm{ag}}$ up to several weeks made no significant changes in structure.

3.2. The Analysis of Ablation Products of Copper. Figure 8 shows the absorption spectra of copper colloids. The sharp and wide peaks in these spectra (curves 1, 2, and 3) indicate the presence of the copper oxides nanostructures $\mathrm{CuO}$ and $\mathrm{Cu}_{2} \mathrm{O}$. Similar features of the spectra were found and discussed in numerous studies of copper nanoparticles synthesis by chemical and other methods. In [27] the increase of the absorption at $260 \mathrm{~nm}$ and $340 \mathrm{~nm}$ was associated with interband transitions in nanocrystallites $\mathrm{Cu}_{2} \mathrm{O}$. Also interband transitions of copper ions are in these ranges [28]. The weak peak around $630-640 \mathrm{~nm}$ was interpreted as the exciton absorption of $\mathrm{Cu}_{2} \mathrm{O}$ (band gap $\approx 2 \mathrm{eV}$ ) [27], and the peak at $\lambda \approx 580 \mathrm{~nm}$ was recorded in [29]. It was assumed that the increase of absorption can be result of both the plasmon resonance of copper nanoparticles and copper ion interband transitions [30]. As for experiments with Zn spectra of colloids with different SDS concentrations (curves 4, 5, 6, and 7) considerably distinguish from spectra of water colloids. The overall level of the absorption increases for colloids with SDS especially in the long wavelength $(>450 \mathrm{~nm})$ spectral region. But the spectrum of colloid with $0.01 \mathrm{M}$ SDS is quite different than other. The degree of the absorbance reduction at $350 \mathrm{~nm}$ wavelengths is much lower than for other colloids, and it is typical for the presence of large-scale fractal structures in this colloid. This fact is confirmed by significant decrease of the absorption during the aging and after the centrifugation of colloid.

XRD patterns and AFM and SEM images show that the solid phase of $0.01 \mathrm{M}$ SDS colloids consists of a twodimensional layered structures with two layers of alkyl sulfate anions chains accommodated between the two cupric hydroxide layers. The formula of this complex is $\left[\mathrm{Cu}_{2}(\mathrm{OH})_{3} \mathrm{DS}^{-}-\mathrm{Cu}_{2}(\mathrm{OH})_{3} \mathrm{CH}_{3}\left(\mathrm{CH}_{2}\right)_{11} \mathrm{OSO}_{3}\right]$. XRD patterns (Figure 9) demonstrate that there are two layered structures with the basal spacing $d=3.887 \mathrm{~nm}$ and $d=$ $3.27 \mathrm{~nm}$

Indeed as follows from estimations in [31] the interlayer size of $3.887 \mathrm{~nm}$ can correspond to bilayered structure with layers of DS anions which are arranged either as partially interdigitated bilayers or tilted to layers of copper hydroxide at the angle about $71^{\circ}$. The similar structure with $d \approx$ $3.92 \mathrm{~nm}$ was obtained chemically in [4]. The interlayer size of $3.27 \mathrm{~nm}$ can correspond to a structure in which the alkyl chains are oriented at the angle about $48^{\circ}$ to the hydroxide layers or are partially interdigitated.

From the analysis of SEM images (Figure 10) and AFM images (Figure 11) it could be concluded that the observed flat structures (platelets) are "sandwiches" of many bilayers of composites. The minimum of platelets thickness was about $8 \mathrm{~nm}$. It should be noted that described structure of organic-inorganic composite of copper was apparently obtained by laser ablation in liquids for the first time.

\section{Conclusion}

The optical spectra, diffraction patterns, and AFM images show dynamics of the formation of nanostructures in the experiments with the powerful copper vapor laser usage. High-power laser output results in a rise of colloid temperature and brings to an intense synthesis of nanoparticles on the basis of zinc and copper (oxides, hydroxides, and layered organic-inorganic composites), to formation of clusters and large (up to hundreds of nanometers or more) complexes with different structures and shapes-fractal aggregates. The qualitative explanation of the features of optical spectra of the studied colloids is possible on the base of the theory of fractals. Specificity of the surfactants usage for the ablation process was demonstrated by the formation of micelles consisting of surfactant molecules and nanoparticles. 
On the one hand the surfactant molecules which surround nanoparticles limit their growth and aggregation. On the other hand there is a possibility of synthesis of various chemical complexes on the basis of the surfactants, water, and metals. In our experiments bilayered zinc hydroxide nanocomposites $\left((\beta)-\mathrm{Zn}(\mathrm{OH})_{2}+\mathrm{DS}\right)$ and two differently shaped bilayered copper composites $\left(\mathrm{Cu}_{2}(\mathrm{OH})_{3} \mathrm{DS}\right)$ were obtained. Copper composites probably were obtained by the laser ablation in the water solution of SDS for the first time.

\section{References}

[1] W. Fujita and K. Awaga, "Reversible structural transformation and drastic magnetic change in a copper hydroxides intercalation compound," Journal of the American Chemical Society, vol. 119, no. 19, pp. 4563-4564, 1997.

[2] M. Okazaki, K. Toriyama, S. Tomura, T. Kodama, and E. Watanabe, "A monolayer complex of $\mathrm{Cu}_{2}(\mathrm{OH})_{3} \mathrm{C}_{12} \mathrm{H}_{25} \mathrm{SO}_{4}$ directly precipitated from an aqueous SDS solution," Inorganic Chemistry, vol. 39, no. 13, pp. 2855-2860, 2000.

[3] S. P. Newman and W. Jones, "Synthesis, characterization and applications of layered double hydroxides containing organic guests," New Journal of Chemistry, vol. 22, no. 2, pp. 105-115, 1998.

[4] E. Kandare, G. Chigwada, D. Wang, C. A. Wilkie, and J. M. Hossenlopp, "Nanostructured layered copper hydroxy dodecyl sulfate: a potential fire retardant for poly(vinyl ester) (PVE)," Polymer Degradation and Stability, vol. 91, no. 8, pp. 17811790, 2006.

[5] H. Usui, T. Sasaki, and N. Koshizaki, "Ultraviolet emission from layered nanocomposites of $\mathrm{Zn}(\mathrm{OH})_{2}$ and sodium dodecyl sulfate prepared by laser ablation in liquid," Applied Physics Letters, vol. 87, no. 6, Article ID 063105, 3 pages, 2005.

[6] K. L. van der Molen, A. P. Mosk, and A. Lagendijk, "Quantitative analysis of several random lasers," Optics Communications, vol. 278, no. 1, pp. 110-113, 2007.

[7] N. Kumar, A. Dorfman, and J. I. Hahm, "Ultrasensitive DNA sequence detection using nanoscale $\mathrm{ZnO}$ sensor arrays," Nanotechnology, vol. 17, no. 12, pp. 2875-2881, 2006.

[8] P. Nalawade, B. Aware, V. J. Kadam, and R. S. Hirlekar, "Layered double hydroxides: a review," Journal of Scientific and Industrial Research, vol. 68, no. 4, pp. 267-272, 2009.

[9] G. W. Yang, "Laser ablation in liquids: applications in the synthesis of nanocrystals," Progress in Materials Science, vol. 52, no. 4, pp. 648-698, 2007.

[10] V. T. Karpuhin, M. M. Malikov, G. E. Val'yano, T. I. Borodina, and O. A. Gololobova, "Investigation of the characteristics of a colloidal solution and its solid phase obtained through ablation of zinc in water by high power radiation from a copper vapor laser," High Temperature, vol. 49, no. 5, pp. 681684, 2011.

[11] P. S. Hale, L. M. Maddox, J. G. Shapter, N. H. Voelcker, M. J. Ford, and E. R. Waclawik, "Growth kinetics and modeling of $\mathrm{ZnO}$ nanoparticles," Journal of Chemical Education, vol. 82, no. 5, pp. 775-778, 2005.

[12] P. Kumbhakar, D. Singh, C. S. Tiwary, and A. K. Mitra, "Chemical synthesis and visible photoluminescence emission from monodispersed $\mathrm{ZnO}$ nanoparticles," Chalcogenide Letters, vol. 5, no. 12, pp. 387-394, 2008.

[13] H. Zeng, W. Cai, Y. Li, J. Hu, and P. Liu, "Composition/structural evolution and optical properties of $\mathrm{ZnO} / \mathrm{Zn}$ nanoparticles by laser ablation in liquid media," Journal of Physical Chemistry B, vol. 109, no. 39, pp. 18260-18266, 2005.

[14] L. Yang, P. W. May, L. Yin, and T. B. Scott, "Growth of selfassembled $\mathrm{ZnO}$ nanoleaf from aqueous solution by pulsed laser ablation," Nanotechnology, vol. 18, no. 21, Article ID 215602, 2007.

[15] H. Usui, Y. Shimizu, T. Sasaki, and N. Koshizaki, "Photoluminescence of $\mathrm{ZnO}$ nanoparticles prepared by laser ablation in different surfactant solutions," Journal of Physical Chemistry B, vol. 109, no. 1, pp. 120-124, 2005.

[16] S. Y. Kim, I. S. Lee, Y. S. Yeon, S. M. Park, and J. K. Song, "ZnO nanoparticles with hexagonal cone, hexagonal plate, and rod shapes: synthesis and characterization," Bulletin of the Korean Chemical Society, vol. 29, no. 10, pp. 1960-1964, 2008.

[17] Y. Chung and W. Kang, "Preparation of $\mathrm{ZnO}$ nanoparticles by laser ablation of dispersed ZnO powder in solution," Journal of the Korean Chemical Society, vol. 50, no. 6, pp. 440-446, 2006.

[18] C. H. Zang, Y. C. Liu, R. Mu et al., "Optical properties of $\mathrm{ZnO}$ nanocrystals embedded in $\mathrm{BaF}_{2}$ film fabricated by magnetron sputtering," Journal of Physics D, vol. 40, no. 18, pp. 55985601, 2007.

[19] H. Zeng, P. Liu, W. Cai, X. Cao, and S. Yang, "Aginginduced self-assembly of $\mathrm{Zn} / \mathrm{ZnO}$ treelike nanostructures from nanoparticles and enhanced visible emission," Crystal Growth and Design, vol. 7, no. 6, pp. 1092-1097, 2007.

[20] S. C. Singh and R. Gopal, "Laser irradiance and wavelengthdependent compositional evolution of inorganic $\mathrm{ZnO}$ and ZnOOH/organic SDS nanocomposite material," Journal of Physical Chemistry C, vol. 112, no. 8, pp. 2812-2819, 2008.

[21] S. Takahashi, H. Wada, A. Noguchi, and O. Odawara, "Increase in the fluorescence intensity of $\mathrm{ZnO}$ nanoparticle by laser irradiation," Materials Letters, vol. 62, no. 19, pp. 3407-3409, 2008.

[22] V. Briois, C. Giorgetti, E. Dartyge et al., "In situ and simultaneous nanostructural and spectroscopic studies of $\mathrm{ZnO}$ nanoparticle and Zn-HDS formations from hydrolysis of ethanolic zinc acetate solutions induced by water," Journal of Sol-Gel Science and Technology, vol. 39, no. 1, pp. 25-36, 2006.

[23] S. V. Karpov and V. V. Slabko, Optical and Photophysical Properties of Fractal-Structured Metal Sols, Russian Academy of Sciences, Siberian Branch, Novosibirsk, Russia, 2003.

[24] S. V. Karpov, A. K. Popov, S. G. Rautian et al., "Finding photomodification silver clusters, selective wavelength and polarization," JETP Letters, vol. 48, no. 10, pp. 528-531, 1988.

[25] C. Liang, Y. Shimizu, M. Masuda, T. Sasaki, and N. Koshizaki, "Preparation of layered zinc hydroxide/surfactant nanocomposite by pulsed-laser ablation in a liquid medium," Chemistry of Materials, vol. 16, no. 6, pp. 963-965, 2004.

[26] H. Usui, T. Sasaki, and N. Koshizaki, "Formation process of platelet nanocomposites with zinc hydroxide and sodium dodecyl sulfate prepared by laser ablation in solution," Chemistry Letters, vol. 35, no. 7, pp. 752-753, 2006.

[27] M. Yin, C. K. Wu, Y. Lou et al., "Copper oxide nanocrystals," Journal of the American Chemical Society, vol. 127, no. 26, pp. 9506-9511, 2005.

[28] A. N. Pestryakov, V. P. Petranovskii, A. Kryazhov, O. Ozhereliev, N. Pfänder, and A. Knop-Gericke, "Study of copper nanoparticles formation on supports of different nature by UV-Vis diffuse reflectance spectroscopy," Chemical Physics Letters, vol. 385, no. 3-4, pp. 173-176, 2004.

[29] T. M. D. Dang, T. T. T. Le, E. Fribourg-Blanc, and M. C. Dang, "The influence of solvents and surfactants on the preparation 
of copper nanoparticles by a chemical reduction method," Advances in Natural Sciences: Nanoscience and Nanotechnology, vol. 2, no. 2, Article ID 025004, 2011.

[30] H. X. Zhang, U. Siegert, R. Liu, and W. B. Cai, "Facile fabrication of ultrafine copper nanoparticles in organic solvent," Nanoscale Research Letters, vol. 4, no. 7, pp. 705-708, 2009.

[31] M. Meyn, K. Beneke, and G. Lagaly, "Anion-exchange reactions of hydroxy double salts," Inorganic Chemistry, vol. 32, no. 7, pp. 1209-1215, 1993. 

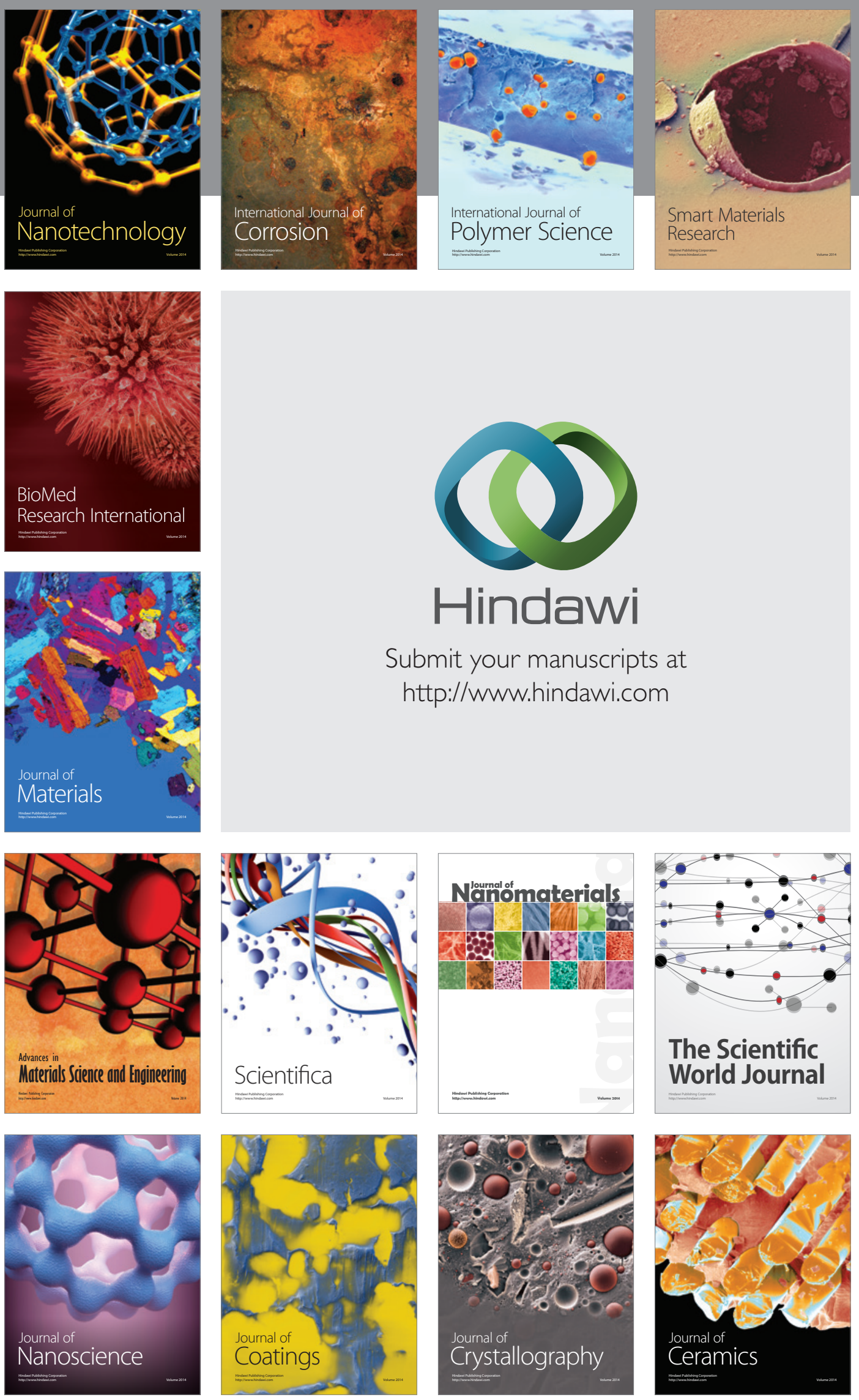

The Scientific World Journal

Submit your manuscripts at

http://www.hindawi.com

\section{World Journal}

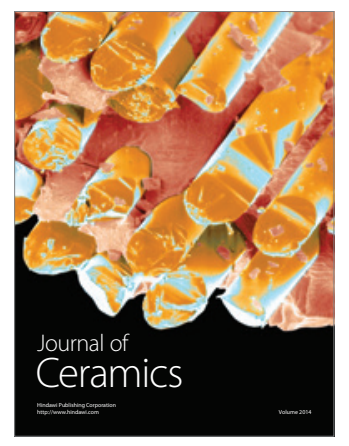

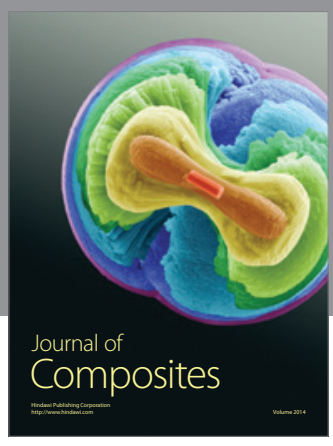
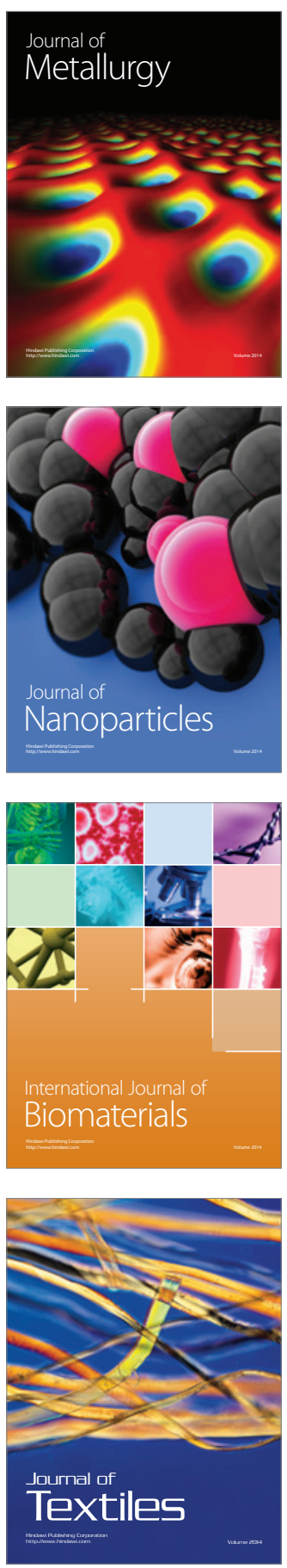